\title{
Papillomavirus infection of roe deer in the Czech Republic and fibropapilloma- associated levels of metallothionein, zinc, and oxidative stress
}

Jiří Král ${ }^{1}$, Hana Band’ouchová ${ }^{1}$, Jiř́i Brichta ${ }^{1}$, Veronika Kováčová1, Karel Ondráček ${ }^{1}$,

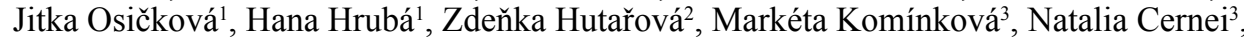
Marie Konečná ${ }^{3}$, Kateřina Tmejová ${ }^{3}$, Ondřej Zítka ${ }^{1}$, Vojtěch Adam ${ }^{3}$, René Kizek ${ }^{3}$, Miša Škorič ${ }^{4}$, Bohuslava Tremlovás, František Treml ${ }^{6}$, Jiří Pikula ${ }^{1}$

\begin{abstract}
${ }^{1}$ University of Veterinary and Pharmaceutical Sciences Brno, Faculty of Veterinary Hygiene and Ecology, Department of Ecology and Diseases of Game, Fish and Bees, ${ }^{2}$ Department of Veterinary Public Health and Animal Welfare, Brno, Czech Republic

${ }^{3}$ University of Technology, Central European Institute of Technology, Brno, Czech Republic ${ }^{4}$ University of Veterinary and Pharmaceutical Sciences, Faculty of Veterinary Medicine, Department of Pathological Morphology and Parasitology, ${ }^{5}$ Faculty of Veterinary Hygiene and Ecology, Department of Vegetable Foodstuffs Hygiene and Technology, ${ }^{6}$ Faculty of Veterinary Medicine, Department of Infectious Diseases and Microbiology, Brno, Czech Republic
\end{abstract}

Received August 24, 2014

Accepted January 14, 2015

\begin{abstract}
The present study aimed at the aetiological diagnosis of skin tumours of roe deer (Capreolus capreolus) in the Czech Republic. A total of 33 roe deer specimens showing skin masses were sampled for histopathology, virus detection and identification using polymerase chain reaction (PCR) and deoxyribonucleic acid sequence (DNA) analysis, and to investigate fibropapillomaassociated levels of metallothionein, zinc and oxidative stress in 2012 and 2013. Ticks (Ixodes ricinus) and deer keds (Lipoptena cervi) were also collected and pooled from sampled game specimens. Ticks found on dogs in hunting grounds under study were pooled into another sample. Skin tumours, ranging from 2 to 10 per inspected specimen and 2 to $5 \mathrm{~cm}$ in size, were classified as fibropapillomas by histopathology. All 33 viral-infection-suspected skin samples from roe deer in South Moravia and South Bohemia were PCR positive. The nucleotide sequences of PCR products were $100 \%$ homologous to the Western roe deer papillomavirus 1 isolate CcPV-1. Ticks and deer keds from positive roe deer and ticks from dogs were PCR and DNA sequence positive for the roe deer papillomavirus. Viral DNA was also demonstrated in one blood sample from a roe deer female. Differences in metallothionein, zinc, taurine and electrochemical index among samples from lesions and normal skin of affected roe deer and negative controls from papillomavirus-non-infected animals were non-significant. While we have demonstrated circulation of specific roe deer papillomavirus in the Czech Republic that results in multiple fibropapillomatous skin tumours, many ecological and epidemiological issues of this wildlife disease still remain unanswered.
\end{abstract}

Capreolus capreolus, Lipoptena cervi, Ixodes ricinus, papillomatosis, skin tumours, hunting dog

The roe deer (Capreolus capreolus) is an important native game ungulate species found throughout most habitats of Europe (Pikula et al. 1997), with estimated spring population and annual bag records in the Czech Republic amounting to 310000 and 120000 specimens, respectively. Importantly, annual mortality reports stand at nearly 40000 in this central European country. In an analysis of mortality of 1606 roe deer specimens in the Czech Republic, it was found that dietary, parasitic, infectious, toxic, and traumatic causes were responsible for 46, 41, 5, 4, and 4\% of deaths, respectively (Sterba et al. 1997).

While infections play a minor role in roe deer mortality, a novel roe deer papillomavirus infection endemic to the Carpathian basin area of Hungary, Austria and Croatia has been recognised (Erdélyi et al. 2009). Phylogenetic analysis placed the roe deer papillomavirus

Address for correspondence:

Prof. MVDr. Jiri Pikula, Ph.D.

Department of Ecology and Diseases of Game, Fish and Bees

Faculty of Veterinary Hygiene and Ecology

University of Veterinary and Pharmaceutical Sciences Brno

Palackého tř. 1/3, 61242 Brno, Czech Republic

Phone: +420 541562655

Fax: +420541562657

E-mail: pikulaj@vfu.cz

http://actavet.vfu.cz/ 
within the Delta-papillomavirus genus (Erdélyi et al. 2008). Fibropapillomatous skin tumours are easy to recognise (Erdélyi et al. 2009), and, to date, the disease has also been reported from Slovak and Czech regions bordering with Hungary and Austria. Where prevalent, it may endanger the economics of trophy hunting because of the repulsive appearance of affected animals. However, there is still a lack of proper diagnosis based on virus identification and genetic analysis from these two new countries of disease occurrence.

The latest research indicates that metallothioneins (MTs) play a role in many pathophysiological processes including viral infections connected with a tumour disease (Theocharis et al. 2003; Krizkova et al. 2009). Interestingly, apart from metal ion homeostasis, detoxification, protection against oxidative damage, and cell proliferation and apoptosis, metallothionein isoforms have been shown to be involved in several aspects of the carcinogenic process, cancer development and progression (Cherian et al. 2003; Theocharis et al. 2003; Krizkova et al. 2008). Elevated MT concentrations in cancer cells are probably related to their increased proliferation and protection against apoptosis (Krizkova et al. 2009). Metallothioneins, a group of low-molecular weight, cysteine-rich intracellular proteins, control the cellular zinc ion levels and proper intracellular $\mathrm{Zn}$ (II) concentration maintains the fragmentation of DNA associated with caspase-3 activity. As the expression of MTs has been linked with tumour spread, it may be a potential prognostic marker for certain tumours (Dutsch-Wicherek et al. 2008). Moreover, the metal ion detoxification function of MTs may interfere with chemotherapy (Theocharis et al. 2003; Eckschlager et al. 2009).

Extensive observations suggest that oxidative stress, chronic inflammation, and cancer are closely linked (Reuter et al. 2010). Taurine, a major cytosolic free amino acid of leukocytes, scavenges for reactive oxidants such as hypohalous acids $\mathrm{HOCl}$ and $\mathrm{HOBr}$ generated by activated neutrophils at sites of inflammation (Nejdl et al. 2013). Electrochemical voltammetry is a non-specific method of evaluation of oxidative stress in biomedicine that allows for comparison of overall antioxidant activity associated with the pathology under study (Pohanka et al. 2011, 2012).

As viral aetiology of fibropapillomatous skin tumours of roe deer from the Czech Republic has not yet been confirmed and nothing is known about metallothionein and zinc concentrations and oxidative stress in this type of tumour in wildlife, the objective of the present study was to detect and identify the roe deer papillomavirus in suspect samples collected in Czech hunting grounds and investigate fibropapilloma-associated concentrations of metallothionein, zinc, taurine, and the electrochemical index. Furthermore, the role of ectoparasites as potential vectors of the roe deer papillomavirus was examined.

\section{Materials and Methods}

\footnotetext{
Laboratory diagnostics of skin tumours included histopathology, PCR and DNA sequence analysis. Paired samples of normal skin and fibropapillomatous tumours were collected from a total of 33 roe deer specimens (15 males and 18 females) from South Bohemia and South Moravia (Czech Republic) in 2012 and 2013. These roe deer (Capreolus capreolus) specimens were killed during the regular hunting season and aged from 3 to 8 years. Other 10 specimens without clinical skin disease, younger than 1 year and with a sex ratio of $1: 1$ were sampled to obtain the negative control of skin. Blood was also sampled by cardiac puncture within half an hour of killing the specimens used in the study. Each skin and fibropapilloma sample was divided into parts for histopathology, virus detection and identification, and measurements of metallothionein and zinc concentrations, oxidative stress and amino acids. Fresh samples for histopathological examination were placed in $10 \%$ buffered formalin, treated using a routine histological technique and embedded in paraffin. Sections of $5 \mu \mathrm{m}$ thickness were made from the paraffin blocks, and these were stained with haematoxylin and eosin. The other parts were stored at $-20{ }^{\circ} \mathrm{C}$ until analysis. The DNA was extracted from approximately $20 \mathrm{~mm}^{3}$ using a commercial kit (DNeasy ${ }^{\mathrm{R}}$ Blood \& Tissue Kit, Qiagen $\mathrm{GmbH}$, Germany) for polymerase chain reaction and sequence analysis.

Ticks (Ixodes ricinus) and deer keds (Lipoptena cervi) were also collected and pooled from individual sampled game specimens. A total of 83 ticks found on dogs used in hunting grounds under study were pooled into another
} 
sample. Prior to DNA extraction to examine ectoparasites for the presence or absence of DNA specific for the roe deer papillomavirus, ticks and keds were washed with physiological saline to remove external contamination.

The PCR assay was performed as described previously (Erdélyi et al. 2008; Erdélyi et al. 2009) using a pair of PCR primers suitable for the detection of cervid papillomavirus DNA, i.e., Paplf (5'-CTGCAGGCTCGTATGTC-3') and Pap1r (5'-CTGCCTCCKACACCTGTGAC-3'). The PCR products were purified using High Pure PCR Product Purification Kit (Roche Applied Science, Mannheim, Germany) and directly sequenced with the primers used for their amplification and BigDye Terminator kit (Applied Biosystems, Foster City, California, USA). The nucleotide sequences of PCR products were then displayed using Chromas Lite 2.1 (Technelysium Pty Ltd, Australia) and compared by the NCBI BLAST alignment search tool with the GenBank DNA database.

Metallothioneins in normal and tumorous skin tissues were determined using the differential pulse voltammetry Brdicka reaction as described previously (Pohanka et al. 2012). For assessment of oxidative stress, square wave voltammetric measurements were performed using PalmSens potentiostat (PalmSens, the Netherlands) connected with the sensor field through a control box (BUT, Czech Republic). The voltage was applied within the range from 0 to $1.1 \mathrm{~V}$ with potential step as well as voltage amplitude of $5 \mathrm{mV}$. Frequency of the waves was $1 \mathrm{~Hz}$. The method was adjusted according to Pohanka et al. (2011). Determination of zinc was carried out on 240FS Agilent Technologies atomic absorption spectrometer (Agilent, USA) with flame atomization. The zinc hollow cathode lamp (Agilent, USA) was operated at the current of $5 \mathrm{~mA}$. Zinc was measured on the primary wavelength of $213.9 \mathrm{~nm}$ with spectral bandwidth of $1.0 \mathrm{~nm}$. Mixture of air and acetylene was used for flame atomization. Deuterium background correction was used and the signal was measured in the integration mode for $2 \mathrm{~s}$. Taurine was measured using an automatic amino acid analyser (AAA 400, Ingos, Prague) according to Nejdl et al. (2013).

The data analysis software Statistica for Windows 10 (StatSoft, Inc., Tulsa, OK, USA) was used to compare concentrations of metallothioneins and zinc in normal skin and those associated with fibropapillomas by one-way analysis of variance (ANOVA) and post hoc analysis of means by the LSD test. Levene's method was used to test for the homogeneity of variances. Non-homogenous parameters were log-transformed prior to analysis and compared with the non-parametric Kruskal-Wallis test. All tests were considered significant or highly significant when resulting in values of $P<0.05$ or $P<0.01$, respectively.

\section{Results}

Skin tumours per inspected specimen ranged from 2 to 10 in numbers and from 2 to $5 \mathrm{~cm}$ in size. Histopathology revealed a dense tissue of fibroblasts/fibrocytes and collagen fibres (Plate II, Fig. 1), with a clear demarcation line between the tumour and normal skin (Plate II, Fig. 2). There were also signs of hyperkeratosis and mild hyperpigmentation, koilocytes containing intranuclear viral inclusions within epidermis, and a mild inflammatory reaction in the dermis (Plate III Fig. 3).

All 33 viral-infection-suspected skin samples collected from roe deer specimens in South Moravia and South Bohemia were PCR positive for the roe deer papillomavirus. The nucleotide sequences of PCR products (701 bp amplicon) indicate 100\% homology to the Western roe deer papillomavirus 1 isolate CcPV-1, complete genome (GenBank accession number EF680235.1). Considering ectoparasites, pooled samples of ticks and deer keds from the above positive roe deer specimens as well as ixodid ticks collected from dogs in the respective hunting habitats were PCR and DNA sequence positive for the roe deer papillomavirus. Viral DNA was also demonstrated in one blood sample from a female roe deer.

Concentrations of metallothionein were determined in normal skin of affected animals, papillomas and negative controls from healthy papillomavirus-non-infected animals. While the highest MT concentrations were found in papillomas (2.6 mg $\cdot \mathrm{g}^{-1}$ of total protein), MT concentrations in normal skin of positive specimens and control animals were by $20 \%$ and 30\% lower (Fig. 4A). A similar situation was observed in zinc concentrations which were the highest in hair as well as tissue samples from papillomas. Zinc concentrations determined in samples of normal skin of positive animals and controls were almost equal (the values amounted to $27.6 \mu \mathrm{g} \cdot \mathrm{g}^{-1}$ and $26 \mu \mathrm{g} \cdot \mathrm{g}^{-1}$, respectively). Hair samples from normal skin of positive animals contained concentrations of zinc approximately $30 \mu \mathrm{g} \cdot \mathrm{g}^{-1}$ higher than controls.

The amount of taurine as a protective agent against oxidative stress was measured and 
compared with the electrochemical index (Fig. 4B). The highest content of both taurine and the electrochemical index expressing the level of oxidative stress was found in papillomas. Taurine concentration in normal skin of positive animals was higher than in healthy controls. While taurine in papillomas achieved the concentration of $10 \mu \mathrm{g} \cdot \mathrm{g}^{-1}$, its concentration in normal skin of affected animals was lower by $20 \%$. Taurine concentration in healthy controls was approximately $60 \%$ lower than in the papillomatous tissue. Mean electrochemical indices of normal skin of positive animals and healthy controls were at similar levels.

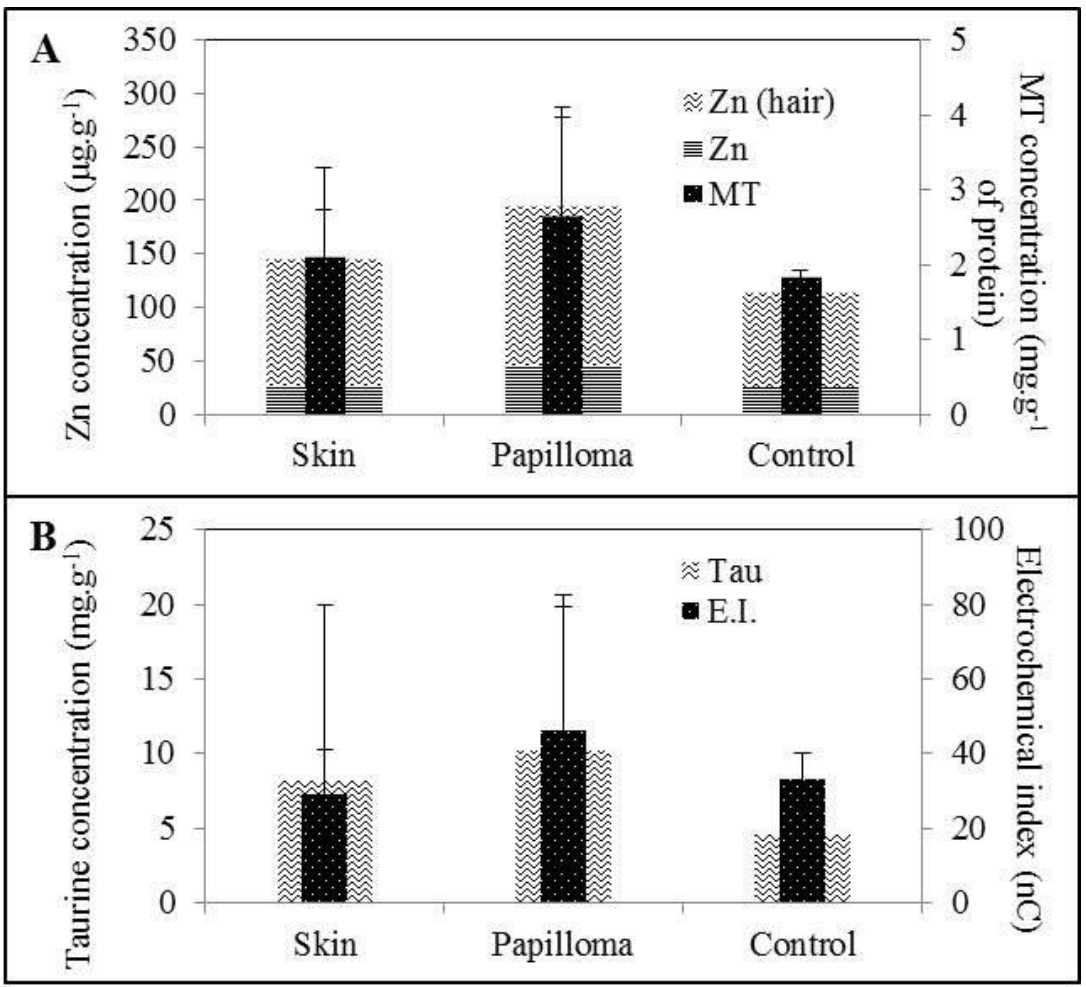

Fig. 4. Differences among samples collected from lesions and normal skin of affected roe deer specimens and negative controls from papillomavirus-non-infected animals. (A) Fibropapilloma-associated levels of metallothionein (MT) and zinc (Zn), and (B) taurine (Tau) and electrochemical index (E.I.)

\section{Discussion}

The present paper provides the first aetiological diagnosis of fibropapillomatous skin tumours of roe deer from the Czech Republic based on papillomavirus DNA detection. The PCR product sequencing revealed 100\% homology to the Western roe deer papillomavirus 1 isolate CcPV-1 identified in Hungary, Austria and Croatia (Erdélyi et al. 2008, 2009). Similar to findings by the above authors, there was no variability of nucleotide sequences from cases examined in the Czech Republic. Likewise, histopathological findings were consistent with those published earlier (Erdélyi et al. 2009). Fibropapillomatosis seems to 
be dependent on the density of roe deer population and the disease distribution is correlated with watercourses (Erdélyi et al. 2009). Both these characteristics apply to habitats in which our positive samples were collected.

It has been suggested that habitats of endemic distribution of roe deer papillomatosis are suitable for arthropod vectors of the disease which might play a significant role in the ecology of the causative virus (Erdélyi et al. 2009). Interestingly, samples of deer keds (Lipoptena cervi) collected and pooled from positive game specimens also harboured the roe deer papillomavirus DNA. To our knowledge, this is the first report of the presence of papillomavirus in this blood-sucking parasite. While deer keds were recognised as vectors of Bartonella spp. in wild and domestic ruminants (Halos et al. 2004), the present finding suggests that they might also play a role in the transmission of papillomavirus in the roe deer population. More importantly, PCR and sequence analysis revealed positive ticks (Ixodes ricinus) in pooled samples collected both from roe deer specimens and hunting dogs. Electron microscopy investigation, however, would be necessary to reveal the exact nature of virus transmission by both ectoparasites. In Europe, Ixodes ricinus is known as a competent vector responsible for transmission of many tick-borne diseases (Lindgren et al. 2000). While non-viraemic transmission of tick-borne infections is possible (Labuda et al. 1993), viral DNA was also demonstrated in one blood sample from a female roe deer and ticks may thus become infected by feeding on viraemic hosts. Likewise, bovine papillomavirus was detected in bloodstream of cattle (Santos et al. 2014). Although papillomaviruses are highly epitheliotropic (Bernard et al. 2010), bovine papillomavirus DNA, for example, has been detected in different body tissues and fluids such as milk, urine, and semen of infected animals (Lindsey et al. 2009). Lymphocytes are known to carry and disseminate papillomavirus infection within an organism and body fluids such as milk and semen (Campo et al. 1994; Stocco dos Santos et al. 1998). The great variety of viral transmission mechanisms including direct and indirect as well as vertical and horizontal options decreases the chances for disease control in a wildlife population. These issues, however, remain to be studied in the roe deer papillomavirus infection.

Investigation of fibropapilloma-associated concentrations of metallothionein, zinc, taurine and the electrochemical index revealed differences among samples collected from lesions and normal skin of affected roe deer specimens and negative controls from papillomavirusnon-infected animals, but without significance. Given the high variability of measured data, a larger sample size would be necessary taking age and sex or nutritional exposure to metallic elements and other pollutants into consideration (Pikula et al. 2010). As shown in Fig. 4, all four measured indicators amounted to the highest value in fibropapillomas. The role of MTs and zinc in cancer development is closely linked and the structure and function of MTs depend strongly on the redox state of zinc and its interactions with proteins (Krizkova et al. 2012). A similar increase in the concentration of MTs has previously been documented in skin melanoma cells both in vivo and in vitro (Krizkova et al. 2008). Likewise, both oxidative stress associated indices, i.e. taurine and the electrochemical index, indicate an increase linked with skin pathology (Pohanka et al. 2012; Nejdl et al. 2013). This finding is in agreement with the observation that antioxidant/oxidative stress indices are more sensitive, yet unspecific, indicators of pathological changes in the organism compared to standard plasma biochemistry (Ondracek et al. 2012).

To conclude, we have demonstrated that the specific roe deer papillomavirus circulates in the roe deer population of the Czech Republic and the infection results in multiple fibropapillomatous skin tumours. New reports of the presence of papillomavirus in bloodsucking parasites should encourage further investigations into the ecology and epidemiology of this viral disease. There is a lack of basic data such as disease prevalence and incidence, current geographic distribution and spread of infection, habitats associated with infection, infectious load at hunting grounds, infection outcome in affected animals, etc. Obviously, 
studies into these issues need a close cooperation between wildlife professionals, hunting ground managers, and the State Veterinary Administration.

\section{Acknowledgement}

The study was supported by the Internal Grant Agency of the University of Veterinary and Pharmaceutical Sciences Brno, Grant No. 26/2012/FVHE.

\section{References}

Bernard HU, Burk RD, Chen Z, van Doorslaer K, zur Hausen H, de Villiers EM 2010: Classification of papillomaviruses (PVs) based on 189 PV types and proposal of taxonomic amendments. Virology 401: 70-79

Campo MS, Jarrett WF, O’Neil W, Barron RJ 1994: Latent papillomavirus infection in cattle. Res Vet Sci 56: $151-157$

Cherian MG, Jayasurya A, Bay BH 2003: Metallothioneins in human tumors and potential roles in carcinogenesis. Mutat Res 533: 201-209

Dutsch-Wicherek M, Sikora J, Tomaszewska R 2008: The possible biological role of metallothionein in apoptosis. Front Biosci 13: 4029-4038

Eckschlager T, AdamV, Hrabeta J, Figova K, Kizek R 2009: Metallothioneins and cancer. Curr Protein Pept Sc 10: $360-375$

Erdélyi K, Bálint A, Dencsö L, Dán A, Ursu K 2008: Characterisation of the first complete genome sequence of the roe deer (Capreolus capreolus) papillomavirus. Virus Res 135: 307-311

Erdélyi K, Dencsö L, Lehoczki R, Heltai M, Sonkoly K, Csányi S, Solymosi N 2009: Endemic papillomavirus infection of roe deer (Capreolus capreolus). Vet Microbiol 138: 20-26

Halos J, Jamal T, Maillard R, Girard B, Guillot J, Chomel B, Vayssier-Taussat M, Boulouis HJ 2004: Role of Hippoboscidae flies as potential vectors of Bartonella spp. infecting wild and domestic ruminants. Appl Environ Microb 70: 6302-6305

Krizkova S, Fabrik I, Adam V, Kukacka J, Prusa R, Chavis GJ, Trnkova L, Strnadel J, Horak V, Kizek R 2008: Utilizing of adsorptive transfer stripping technique Brdicka reaction for determination of metallothioneins level in melanoma cells, blood serum and tissues. Sensors-Basel 8: 3106-3122

Krizkova S, Fabrik I, Adam V, Hrabeta J, Eckschlager T, Kizek R 2009: Metallothionein-a promising tool for cancer diagnostics. Bratisl Med J 110: 93-97

Krizkova S, Ryvolova M, Hrabeta J, Adam V, Stiborova M, Eckschlager T, Kizek R 2012: Metallothioneins and zinc in cancer diagnosis and therapy. Drug Metab Rev 44: 287-301

Labuda M, Nuttall PA, Kožuch O, Elečková E, Williams T, Žuffová E, Sabó A 1993: Non-viraemic transmission of tick-borne encephalitis virus: a mechanism for arbovirus survival in nature. Experientia 49: 802-805

Lindgren E, Tälleklint L, Polfeldt T 2000: Impact of climatic change on the northern latitude limit and population density of the disease-transmitting European tick Ixodes ricinus. Environ Health Perspect 108: 119-123

Lindsey CL, Almeida ME, Vicari CF, Carvalho C, Yaguiu A, Freitas AC, Beçak W, Stocco RC 2009: Bovine papillomavirus DNA in milk, blood, urine, semen, and spermatozoa of bovine papillomavirus-infected animals. Genet Mol Res 8: 310-318

Nejdl L, Sochor J, Zitka O, Cernei N, Ruttkay-Nedecky B, Kopel P, Babula P, Adam V, Hubalek J, Kizek R 2013: Spectrometric and chromatographic study of reactive oxidants hypochlorous and hypobromous acids and their interactions with taurine. Chromatographia 76: 363-373

Ondracek K, Bandouchova H, Damkova V, Hilscherova K, Kral J, Osickova J, Mlcakova V, Pohanka M, Skochova H, Vitula F, Treml F, Pikula J 2012: Risk of combined exposure of birds to cyanotoxins, acetylcholinesterase inhibitors and anticoagulants. Neuroendocrinol Lett 33: 155-160

Pikula J, Beklová M, Sterba F, Bus A, Brandstatter L 1997: Ecological conditions of distribution and population density of roe deer (Capreolus capreolus) in the Czech and Slovak Republics. In: $32^{\text {nd }}$ International Symposium of Societa Italiana per il Progresso della Zootechnica on Animal Production: Advances in Technology, Accuracy and Management. Biofutur Elsevier, Paris, pp. 211-216

Pikula J, Zukal J, Adam V, Bandouchova H, Beklova M, Hajkova P, Horakova J, Kizek R, Valentikova L 2010: Heavy metals and metallothionein in vespertilionid bats foraging over aquatic habitats in the Czech Republic. Environ Toxicol Chem 29: 501-506

Pohanka M, Band“ouchova H, Vlckova K, Karasova JZ, Kuca K, Damkova V, Peckova L, Vitula F, Pikula J 2011: Square wave voltammetry on screen printed electrodes: comparison to ferric reducing antioxidant power in plasma from model laboratory animal (grey partridge) and comparison to standard antioxidants. J Appl Biomed 9: $103-109$

Pohanka M, Hynek D, Kracmarova A, Kruseova J, Ruttkay-Nedecky B, Sochor J, Adam V, Hubalek J, Masarik M, Eckschlager T, Kizek R 2012: Voltammetry assay for assessment of oxidative stress linked pathologies in brain tumor suffered childhood patients. Int J Electrochem Sci 7: 11978-11992

Reuter S, Gupta SC, Chaturvedi MM, Aggarwal BB 2010: Oxidative stress, inflammation, and cancer: How are 
they linked? Free Radical Bio Med 49: 1603-1616

Santos EUD, Silva MAR, Pontes NE, Coutinho LCA, Paiva SSL, Castro RS, Freitas AC 2014: Detection of different bovine papillomavirus types and co-infection in bloodstream of cattle. Transbound Emerg Dis. In press, DOI: 10.1111/tbed.12237

Sterba F, Bus A, Brandstatter L, Pikula J 1997: Analysis of main mortality causes of roe deer (Capreolus capreolus) in the Czech Republic. In: 32 $2^{\text {nd }}$ International Symposium on Animal Production: Advances in Technology, Accuracy and Management. Biofutur Elsevier, Paris, pp. 217-224

Stocco dos Santos RC, Lindsey CJ, Ferraz OP, Pinto JR, Mirandola RS, Benesi FJ, Birgel EH, Pereira CA, Beçak W 1998: Bovine papillomavirus transmission and chromosomal aberrations: an experimental model. J Gen Virol 79: 2127-2135

Theocharis SE, Margeli AP, Koutselinis A 2003: Metallothionein: a multifunctional protein from toxicity to cancer. Int J Biol Markers 18: 162-169 
Plate II

Král J. et al.: Papillomavirus ... pp. 105-111

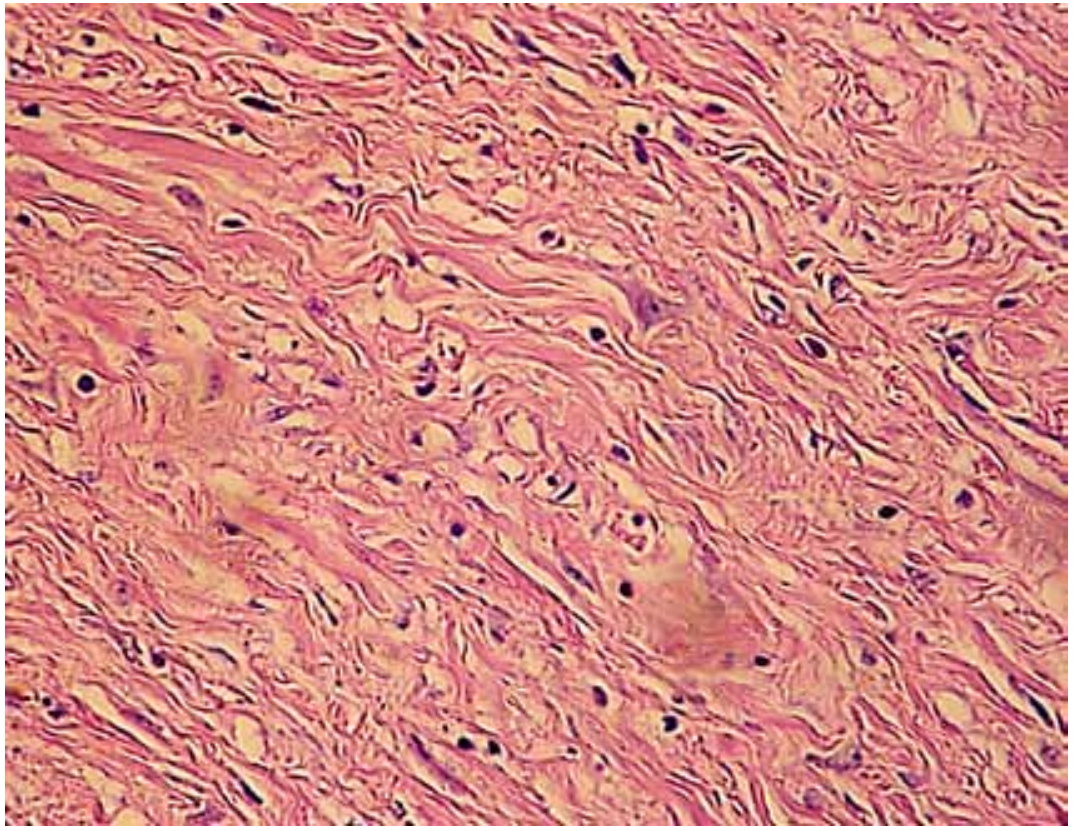

Fig. 1. Dense tissue of fibroblasts/fibrocytes and collagen fibres in the main fibropapilloma mass. Haematoxylin and eosin stain; $\times 400$ magnification.

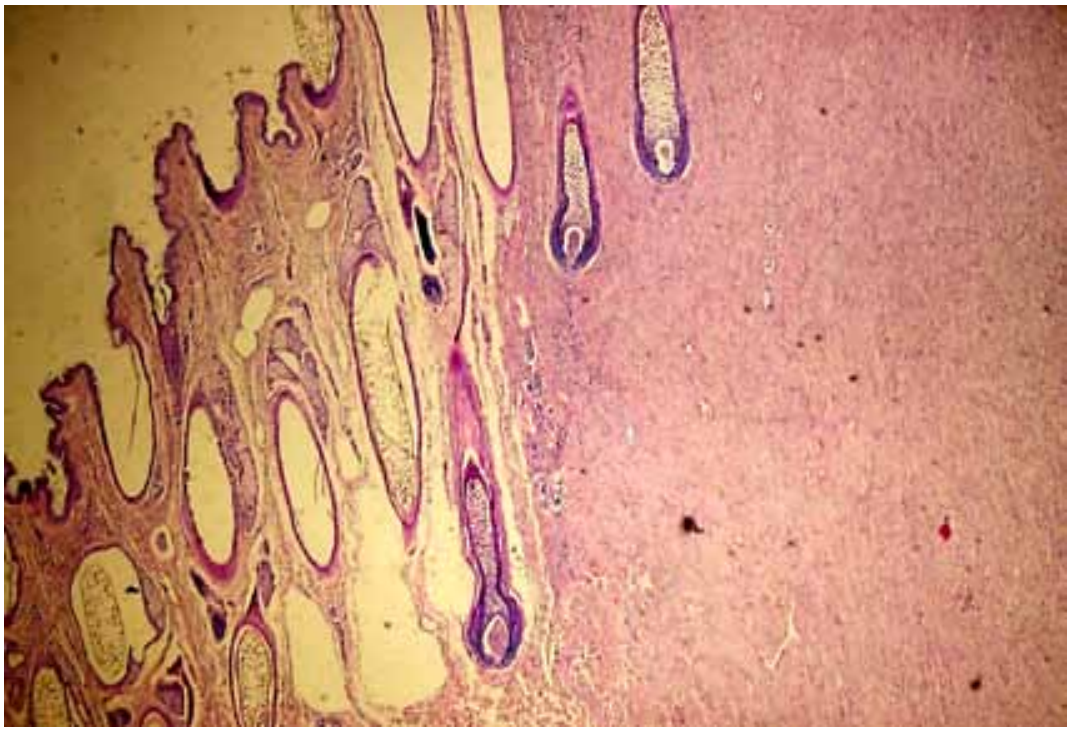

Fig. 2. A clear line of demarcation between fibropapilloma and normal skin. Haematoxylin and eosin stain; $\times 40$ magnification. 


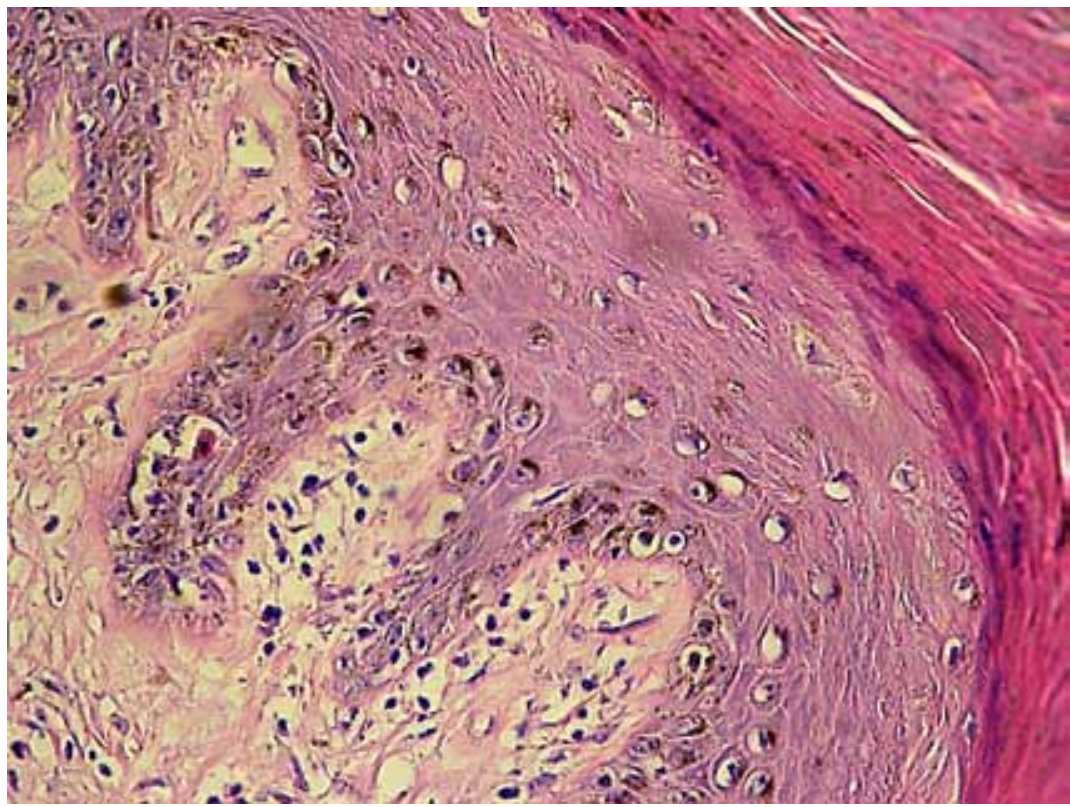

Fig. 3. Hyperkeratosis and mild hyperpigmentation, koilocytes containing intranuclear viral inclusions within epidermis, and a mild inflammatory reaction in the dermis. Haematoxylin and eosin stain; $\times 400$ magnification. 